\title{
Research Progress on Remediation of Heavy Metal Polluted Soils with Mining Ecotype Sedum alfredii
}

\author{
Lu Zhang ${ }^{1, a}$, Herong Gui ${ }^{1, b}$, Haojie Shi ${ }^{*}, \mathrm{c}$ and Han Ding ${ }^{2, \mathrm{~d}}$ \\ ${ }^{1}$ College of Earth Science and the Environment, Anhui University of Science and Technology, \\ Huainan, 232001, China \\ ${ }^{2}$ School of agriculture and Food Science, Zhejiang A\&F University, Lin'an, 311300, Hangzhou, \\ Zhejiang, China \\ a648158579@qq.com, bif557@163.com, cmvp8851@126.com, d812495602@qq.com, \\ ${ }^{*}$ Corresponding author
}

\begin{abstract}
Keywords: Sedum alfredii, Heavy Metal Pollution, Soil, Plant Remediation
Abstract. Plant remediation is a new developed technology for remediation of heavy metal contaminated soil and become a hot spot in this field. Mining ecotype Sedum alfredii Hance can enrich heavy metal ion of contaminated soil and have advantages of large biomass, fast growth, wide adaptability and multiple harvest. It is a good material for remediation of heavy metal contaminated soil and a good model to research the mechanism of super heavy metal accumulation in plants. In this paper, the mechanism of activation and absorption of heavy metals and the optimization of heavy metal repair efficiency in $S$. alfredii were reviewed and the shortcomings and prospects of the current research were also summarized. It provides an important reference for the further development of plant remediation of heavy metal contaminated soil.
\end{abstract}

\section{Introduction}

Soil is an important natural resource for human survival. Due to the rapid development of industrialization in China, a large part of China's arable land has been polluted by heavy metal under the influence of industrial pollution, traffic pollution, living garbage pollution and so on. Heavy metal pollution will not only affect the growth and development of plants, but also be enriched by food chain and has influences of biomagnification. The heavy metal enters the human body through the food, destroys the human nervous system, the immune system, the skeleton system and so on, causes the enormous harm to the human health. Therefore, it is urgent to restore the heavy metal contaminated soil for the build a resource conserving and environment-friendly society. However, the traditional method of soil remediation usually need large investment, but the effect is not significant and destroy the soil structure [1]. In contrast, plant remediation seems a preferable way to solve the problem. Plant remediation refers to transfer heavy metals from soil to the upper parts of green plants and to realize the transfer of heavy metals in the soil. It has the advantages of low cost, no secondary pollution, saving land resources, environment-friendly and sustainable development, so it has become the frontier and hotspot of current research [2-5]. Plant remediation based on the study of hyperaccumulators [6]. However, most of the super-accumulation plants with relatively small biomass, root is not well developed, can not be put into large-scale production practice. Mining ecotype Sedum alfredii Hance can not only enrich a variety of heavy metals such as $\mathrm{Cd}^{2+}, \mathrm{Pb}^{2+}$, but also has several good characteristics, such as a large biomass, perennial, asexual reproduction and suitable for harvesting. Based on a variety of fine features of the mining ecotype Sedum alfredii, it is a good material for the implementation of the hyperaccumulation mechanism [7-10]. Study of the repair mechanism of heavy metal pollution in $S$. alfredii could realize the green restoration of heavy metal pollution to ensure the safe production of agricultural products. Because of the increasing importance of production application, its important research value is increasingly prominent. 


\section{The mechanism of heavy metals activation and absorption of mining ecotype $S$. alfredii}

It was reported that the extracted $\mathrm{Zn}^{2+}$ and $\mathrm{Cd}^{2+}$ contents of rhizosphere soil of mining ecotype $S$. alfredii were significantly decreased. At the same time, the amount of heavy metal accumulation in the aboveground part of the soil was significantly higher than that of the rhizosphere soil. It meant that insoluble $\mathrm{Zn}^{2+}$ and $\mathrm{Cd}^{2+}$ were constantly activated and absorbed in rhizosphere of mining ecotype of $S$. alfredii [11]. It was indicated mining ecotype $S$. alfredii is able to activate rhizosphere insoluble heavy metals into free heavy metals and increase the absorption efficiency of heavy metals. However, the mechanism of activation insoluble heavy metals in rhizosphere soils of mining ecotype of $S$. alfredii still need further research. Most hyperaccumulator plants activate heavy metals by the following aspects:

\section{Root exudates acidified rhizosphere soils}

Soil heavy metal pollutants mostly exist in solid compounds, such as silicate, aluminate, carbonate etc.. With the decrease of soil $\mathrm{pH}$, the release of heavy metals from the carbonate and hydroxide bound states increases, while the adsorption of metal ions is also promoted. Heavy metal ions is toxic to plants, so heavy metal poisoning plants often occurred in acid soil [12]. Rhizosphere $\mathrm{pH}$ were influenced by the uneven anion and cation in plant absorption of inorganic nutrients and the $\mathrm{CO}_{2}$ produced by the soil microbe and plant [13]. The main root exuded organic acids of mining ecotype $S$. alfredii are malic acid, oxalic acid and tartaric acid, while tartaric acid was not detected in non mining ecotype $S$. alfredii root exudates. Moreover, the contents of $\mathrm{Zn}^{2+}, \mathrm{Pb}^{2+}$ and $\mathrm{Cd}^{2+}$ in plants were significantly positively correlated with the contents of oxalic acid and tartaric acid in root exudates. It indicated that the oxalic acid and tartaric acid in the root could promote the activation of heavy metals and the absorption and transportation of $\mathrm{Zn}^{2+}, \mathrm{Pb}^{2+}$ and $\mathrm{Cd}^{2+}[14]$.

\section{Rhizosphere microorganism}

There were significant differences in the microenvironment and non rhizosphere of plant rhizosphere and the different microenvironment resulted in different microbial community in rhizosphere. In the metabolic process, the organic substance secreted by the soil increased the growth and diversity of rhizosphere microorganisms. The number and activity of soil microbes significantly affected the bioavailability of heavy metals. Because microorganisms can produce some acid, small molecular substances and organic matter in the metabolic process, which can improve the ability of plants to improve the ability of heavy metals [15]. Rhizosphere microorganisms of S.alfredii can enhance the absorption efficiency of heavy metals. In the heavy metal contaminated soil, the soil enzyme activity of rhizosphere soil was significantly higher than that in non-rhizosphere soil [11]. This indicated that the activity of rhizosphere microorganisms increased after planting S.alfredii, which increased the activation ability of refractory heavy metals.

\section{The optimization of heavy metal absorption}

\section{Fertilization}

Fertilization can improve soil fertility and increase crop yields, improve soil nutrients and promote plant growth and development. Numerous studies have shown that fertilization can improve the efficiency of super-accumulated plants in remediation of contaminated soils [16]. Shen et al. used orthogonal experiments to study the effects of different fertilizers and their interactions on the growth of $S$. alfredii and the remediation efficiency of $\mathrm{Zn}^{2+}$ and $\mathrm{Cd}^{2+}$ contaminated soils by $\mathrm{N}, \mathrm{P}$ and $\mathrm{K}$ nutrient regulation. The application of $\mathrm{N}$ fertilizer was beneficial to the increase of biomass in the upper part of mining ecotype $S$. alfredii, which was not conducive to the increase of heavy metal concentration; The application of low-dose P fertilizer not only promoted the growth of mining ecotype S. alfredii, but also promoted the accumulation of $\mathrm{Zn}^{2+}$ in the shoot; Although the application of $\mathrm{K}$ fertilizer was not conducive to the increase of the biomass of the upper part of the southeastern landscape, the application of high $\mathrm{K}$ fertilizer could increase the $\mathrm{Zn}^{2+}, \mathrm{Cd}^{2+}$ concentration and accumulation in the shoot [17]. 


\section{Transgenic improvement}

It is well-known that heavy metal hyperaccumulators have the disadvantages of low biomass, low repair efficiency and difficult to put into large-scale production practice. The use of transgenic technology to improve the traditional hyperaccumulator can improve the efficiency and rate of super-accumulation of plants [18]. The research on the accumulation of heavy metals related genes can lay a good foundation for the transgenic S. alfredii [19-21].

\section{Intercropping}

Intercropping is a traditional agricultural planting technology in China. It mainly uses the complementary function of the plant root system and the upper part of the structure to make full use of light energy, space and time resources to increase crop yield. A number of experiments show that mixed cropping with maize significantly increased $\mathrm{Zn}^{2+}$ uptake and accumulation of $S$. alfredii [11, 22-23]. Jiang et al. found that heavy metal absorption of aboveground parts of $S$. alfredi intercropping with maize and soybean were approximately 1.68-1.87 times higher than that of single planting $S$. alfredii. It indicated that the absorption of heavy metals by hyperaccumulators can be improved to a certain extent by intercropping [24].

\section{Conclusions}

The advantages of plant remediation will be paid more and more attention, the screening of the plant that used to the remediation of contaminated soil will be more and more stringent. The rate of asexual reproduction of $S$. alfredii, which is dominated by plant buds, is very fast and can form a good coverage on the ground with a shorter growth period. Its coverage is almost $100 \%$, and has a perennial, suitable for cutting characteristics and is a good material for the implementation of plant remediation and the study of hyperaccumulation mechanisms [7-10]. However, most of the studies on the absorption and enrichment of heavy metals in $S$. alfredii are mostly confined to physiology. The mechanism of transporting heavy metals such as cadmium, zinc and lead in plants is not completely clear. With the rapid development of modern molecular biology and biotechnology, cadmium, zinc, lead and other heavy metals in the plant in the specific transport accumulation mechanism will be more clear. In the future, it is necessary to further study the genes that are closely related to the absorption of zinc and cadmium in S. alfredii, and to improve the efficiency of the restoration in the genetic level, and to lay the theoretical foundation for the application of $S$. alfredii to soil remediation.

\section{Acknowledgements}

This work was financially supported by the Natural Science Foundation of China (grant number 31301619).

\section{References}

[1] H.M. Chen: Science press. (1996), 17-25. In Chinese.

[2] A.J.M. Baker, S.P. Mcgrath, C. Sidoli, and R.D. Reeves: Res Conserv Recycl (1994), 41-49.

[3] D.E. Salt, M. Blaylock, N.P. Kumar, V. Dushenkov, B.D. Ensley, and I. Chet, Nature Biotechnology (1995), 468.

[4] X.X. Long, X.E. Yang and W.Z. Ni: Current situation and prospect on the remediation of soils contaminated by heavy metaols. Chinese Journal of Applied Ecology, (2002), 757-762. In Chinese.

[5] S.P. McGrath, and F.J. Zhao: Current Opinion in Biotechnology, (2003), 227-282.

[6] S.D. Conningham, W.R. Berti and J.W. Huang: Bio/Technology, (1995), 393-397. 
[7] Y.H. Xiong, X.E. Yang and Z.Q Ye: Jour. of Northwest Sci-Tech Univ. of Agri. and For. (Nat. Sci. Ed.), (2004), 101-106. In Chinese.

[8] X.E. Yang, X.X. Long and W.Z. Ni: Chinese Science Bulletin, (2002), 1003-1006. In Chinese.

[9] X.X. Long, X.E. Yang and Z.Q. Ye: Acta Botanica Sinc.A, (2002),152-157.

[10] H.B. Ye, X. E. Yang and Bing Ye: Journal of Agro-Environment Science, (2003), 513-518. In Chinese.

[11] T.Q. Li, N. Zhu and X.E. Yang: Journal of Soil and Water Conservation, (2007), 112-117 In Chinese.

[12] R.D. Harter: Soil Sci.Soc.Am.J., (1983) 47-51.

[13] H. Marschner: Academic Press.San Diego. CA. USA. (1995).

[14]T.Q. Li: Zhejiang University (2005). In Chinese.

[15] S.N. Whiting and M.P. DeSouza: Environ. Sci. Technol., (2001), 3144-3150.

[16] A.O. Fayiga, L.Q. Ma and B. Rathinasabapathi: Environmental and Experimental Botany, (2008), 231-237.

[17] L.B. Shen, L.H. Wu and X.R. Shen: Soils, (2011), 221-225. In Chinese.

[18] L.J. Cai, Z.X. Fan and X.Q. Quan: GUIHAIA, (2009), 658-663. In Chinese.

[19] M.Y. Liu, G.R. Qiao and J. Jiang: Forest Research, (2012), 332-338. In Chinese.

[20] Y.E. Chao: Zhejiang University, (2008). In Chinese.

[21] T. Zhao, X.J. Han and M.Y. Liu: Journal of Zhejiang A\&F University, (2015),25-32. In Chinese.

[22] X.M. Liu, Q.T. Wu and M.K.Banks: International Journal of Plant remediation, (2005), 43-53.

[23] Q.T. Wu, Z.B. Wei and Y. Ouyang. Water Air Soil Pollut, (2007), 131-139.

[24] C.A. Jiang, Q.T. Wu and S.H. Wu: China Environmental Science, (2009), 985-990. In Chinese. 